\title{
树轮木质部解剖特征及其与环境变化的关系
}

\author{
朱良军 ${ }^{1}$ 李宗善 $^{2}$ 王晓春 $^{1^{*}}$ \\ ${ }^{1}$ 东北林业大学生态研究中心, 哈尔滨 $150040{ }^{2}$ 中国科学院生态环境研究中心城市与区域生态国家重点实验室, 北京 100085
}

摘 要 树轮木质部解剖特征是树轮在细胞、亚细胞尺度上的表征, 其往往能从微观尺度解释树轮宽度等宏观结构的变化。 因此, 探讨木质部解剖特征与环境变化的关系, 可为年轮气候学统计结果提供生理解释, 为研究树木生长对气候变化的适应 过程与响应策略提供新视野。该文以树轮木质部解剖特征与气候关系为主线, 概述了木质部解剖特征记录环境信号的基本原 理和机制, 阐述了木质部解剖过程中涉及的基本方法, 探讨了木质部解剖特征与气候因子的关系, 就现有研究中存在的问题 指出今后可能的研究方向: (1)探寻径向和切向上木质部解剖特征的时空变异及其与环境变化的关系; (2)探索植物对环境塑性 响应的阈值及其响应策略及适应过程; (3)探寻各树轮代用指标间的协同与拮抗作用及气候响应差异的形成机理, 确定各时期 主要气候因子对树轮形成的具体作用及贡献量。

关键词 细胞年表; 木质部解剖; 水力结构; 全球变化; 塑性响应; 树轮

引用格式: 朱良军, 李宗善, 王晓春 (2017). 树轮木质部解剖特征及其与环境变化的关系. 植物生态学报, 41, 238-251. doi: 10.17521/cjpe.2016.0198

\section{Anatomical characteristics of xylem in tree rings and its relationship with environments}

ZHU Liang-Jun ${ }^{1}$, LI Zong-Shan ${ }^{2}$, and WANG Xiao-Chun ${ }^{1 *}$

${ }^{1}$ Center for Ecological Research, Northeast Forestry University, Harbin 150040, China; and ${ }^{2}$ State Key Laboratory of Urban and Regional Ecology, Research Center for Eco-Environmental Science, Chinese Academy of Sciences, Beijing 100085, China

\begin{abstract}
The anatomical traits of xylem are the characteristics of tree rings at the cellular and subcellular scales, and are often reflection of environmental signals. Studying the relationships between anatomical traits of xylem and environmental change not only provide physiological explanations to the statistics in dendroclimatology, but can also provide a new vision for studying the adaptation process and response strategies of tree growth to climate change. In this paper, with the relationships between the anatomical characteristics of xylem in tree-rings (cell chronology) and climate change as a main thread, we first outline the basic principles and mechanisms of wood anatomical features to record environmental signals, and expounded the basic methods involved in the process of xylem anatomy. Secondly, we discuss the relationship between the anatomical features of xylem and climate factors. We then propose the following as possible directions of future research based on the existing knowledge gap in the topical area: (1) to explore the temporal and spatial variations in the anatomical characteristics of xylem in tree-rings along radial and tangential directions and the relationships with environmental changes; (2) to explore the threshold of tree growth response to environmental plasticity and adaptation processes; (3) to assess the synergistic and antagonistic effects as well as the formation mechanisms of climate response among different tree-ring proxies, and to determine the specific roles and contributions of major climatic factors during different periods of tree-ring formation.
\end{abstract}

Key words cell chronologies; xylem anatomy; hydraulic architecture; global change; plastic responses; tree-ring

Citation: Zhu LJ, Li ZS, Wang XC (2017). Anatomical characteristics of xylem in tree rings and its relationship with environments. Chinese Journal of Plant Ecology, 41, 238-251. doi: 10.17521/cjpe.2016.0198

树轮具有定年准确、连续性强、分辨率高、易 于获取和复本量大等优点, 其宽度、密度以及同位 素含量等能够准确记录周围环境的变化(Fritts,
1976)。全球变化背景下, 树轮是研究树木生长与气 候变化关系的重要资料, 更是准确评估气候变化情 境以及物种响应策略与适应性的关键(Fonti et al.,

收稿日期Received: 2016-06-12 接受日期Accepted: 2017-01-03

* 通信作者Author for correspondence (E-mail: wangx@nefu.edu.cn) 
2010), 已被广泛用于全球变化以及古气候研究 (Esper et al., 2002; Briffa et al., 2004; Moberg et al., 2005; Yang et al., 2014)。树轮是众多环境因子在不 同时段内综合作用的结果, 很难确定某一特定环境 因子在特定时期内对树木生长的影响(de Luis et al., 2011)。树轮气候学研究中常用表征年际变化的指标 (如宽度、密度以及同位素含量等)与亚年际尺度(候、 月或季节)的气候因子做响应分析或重建亚年尺度 上的古气候; 但这种统计学上的年轮-气候“响应”关 系, 常因缺乏内在机制或生理学解释而受质疑 (Fritts, 1976)。此外, 传统树轮气候学研究强调限制 地点采样, 这些区域树木往往年龄较大且具有更强 的气候代表性(Fritts, 1976; Esper et al., 2002; Briffa et al., 2004; Yang et al., 2014); 但随着树轮研究工 作的逐渐增多, 理想的树轮研究场所愈来愈少, 研 究工作不得不在一些响应不太敏感的非限制区开 展, 树轮研究遇到了前所未有的瓶颈(Liang et al., 2013)。树轮中记载了大量的气候或环境信息, 传统 树轮代用指标中记录的环境信号仅占一小部分, 如 何充分挖掘树轮中记录的环境信号也是目前亟待解 决的问题。

树轮解剖是基于树轮年代学与木材解剖学方 法, 以获得定年年轮序列上细胞尺度解剖特征(如 导管大小、密度、细胞壁厚度和组织含量等), 并通 过其时间(年内或年际尺度)序列分析树木生长与环 境变化关系的一种多学科方法(Fonti et al., 2010)。 探究树轮解剖特征与环境因子的潜在关系是解决上 述问题的关键, 也是当前树轮生态学研究的一个重 要内容(Fonti et al., 2010)。木质部解剖特征是树轮 在细胞尺度上的分量, 许多解剖特征已被证实能准 确记录与传统代用指标不同或更强的环境信息 (Campelo et al., 2010; Fonti et al., 2010; Abrantes et al., 2013; Liang et al., 2013; Venegas-González et al., 2015); 尤其是在非限制性地点, 木质部解剖特征具 有巨大的应用潜能(Liang et al., 2013)。树轮解剖使 传统树轮研究在时间上由年际尺度精确到月或季节 尺度, 空间上由整个生长轮分辨到细胞或亚细胞尺 度(Fonti et al., 2010), 开展此类研究既有利于进一 步揭示树轮-气候响应关系, 为树轮气候学机制与 机理研究奠定基础, 为传统年轮-气候关系及古气 候重建研究开辟新天地, 又可为研究全球气候变化 情境下物种的适应过程与响应策略提供新视野, 为
科学评估未来气候变化对植被的影响提供依据 (Fritts, 1976; Fonti et al., 2010; Liang et al., 2013)。因 此, 本文综述了树轮木质部解剖特征记录气候或环 境信息的机理、木质部解剖特征研究的手段与方法、 解剖特征的选取与标准化、主要解剖特征与气候变 化关系以及未来展望等内容, 以求为进一步开展树 轮木质部解剖研究提供参考。

\section{1 木质部解剖特征记录环境信号的基本原 理及机制}

\section{1 木质部解剖特征对环境的塑性响应过程及分类}

维管植物形成层为双向活动模式, 可向内形成 木质部, 向外形成韧皮部, 其活动受基因(Ursache et al., 2013)和环境(Rossi et al., 2008)共同控制。环境 (气候)变化能够通过影响植物体内的各种生理进程, 直接或间接地影响形成层活动(树轮解剖特征的形 成), 使树体的结构和功能(如年轮宽度或密度等宏 观特征)发生改变, 以适应当前环境(图1)。如生长季 前或生长季的低降水或高温(干旱胁迫)能直接或间 接地影响多种生理过程, 使部分树木管胞直径变小 且数量减少, 最终形成窄轮(Fritts, 1976)。正是这种 塑性响应关系, 确保了树轮解剖特征能够准确记录 周边环境(气候)的高频变化(Fonti et al., 2010)。需要 强调的是, 这种塑性响应关系存在一定的阈值范围, 环境变化超出该阈值将造成树体发生不可逆伤害甚 至死亡(Fonti et al., 2010), 如严重的霜冻灾害。此 外, 树轮微观解剖特征能够随外界环境变化而塑性 改变, 当这种改变能够适应现有气候时, 植物能够 正常生长; 而当这种改变不足以适应现有气候时, 树木将会出现衰退或死亡(图1)。

根据外部环境事件是否具有连续性, 可将环境 对树轮解剖特征的影响分为不连续的环境事件影响 和连续环境事件影响两类(Fonti et al., 2010)。不连 续环境事件往往危害较大, 常在年轮中留下某些特 殊的“痕迹”。学者们常利用这些“痕迹”重建特殊的 环境事件, 如林火(Smith \& Sutherland, 1999)、虫灾 (Esper et al., 2007)、干旱(Martin-Benito et al., 2013)、 洪灾(Arbellay et al., 2010; Wertz et al., 2013)及霜冻 事件(D’Arrigo et al., 2001)。然而, 连续的环境变化 (如温度或降水等)往往能被连续的树轮解剖特征序 列(即细胞年表)所记录(Battipaglia et al., 2010; Matisons et al., 2012; Liang et al., 2013)。多个树轮木质 


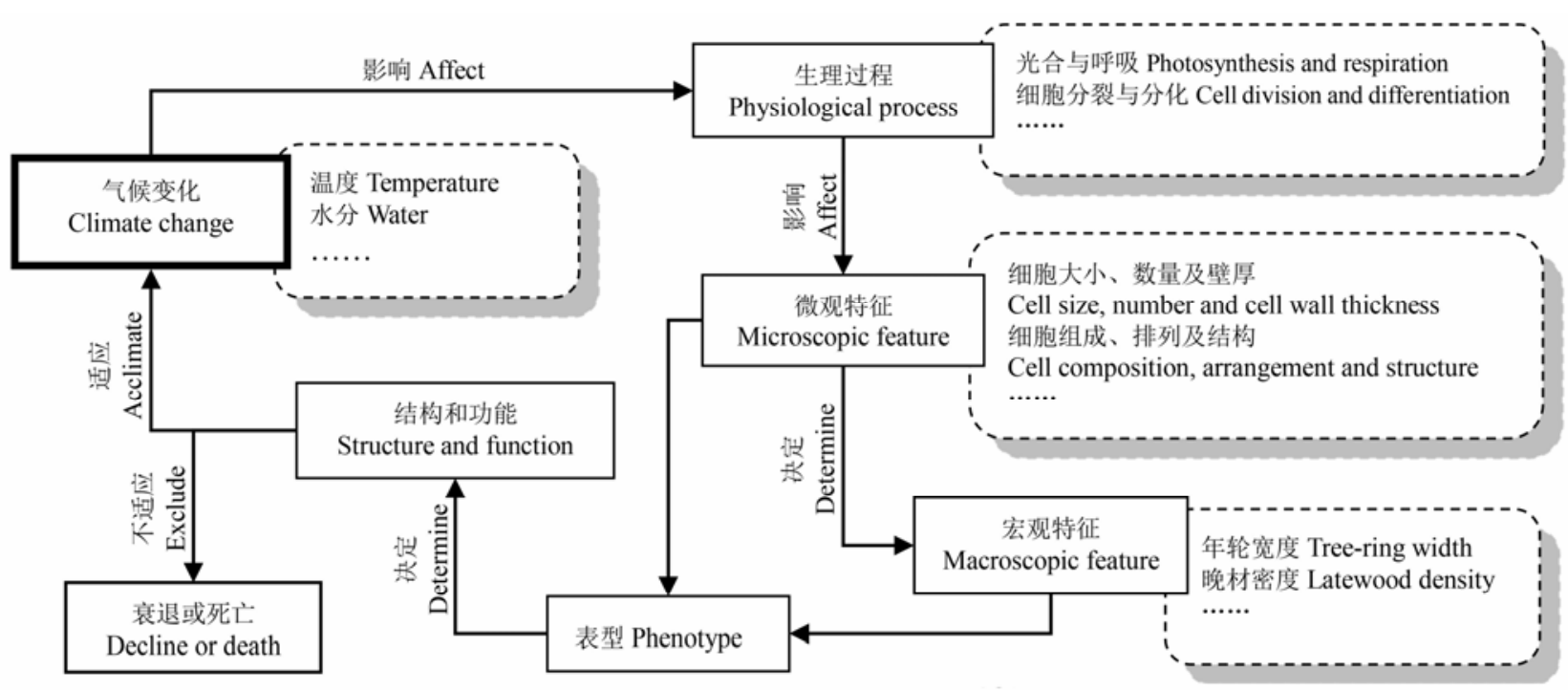

图1 树轮解剖特征对气候变化的响应过程。

Fig. 1 The response process in anatomical characteristics of tree-rings to climate change.
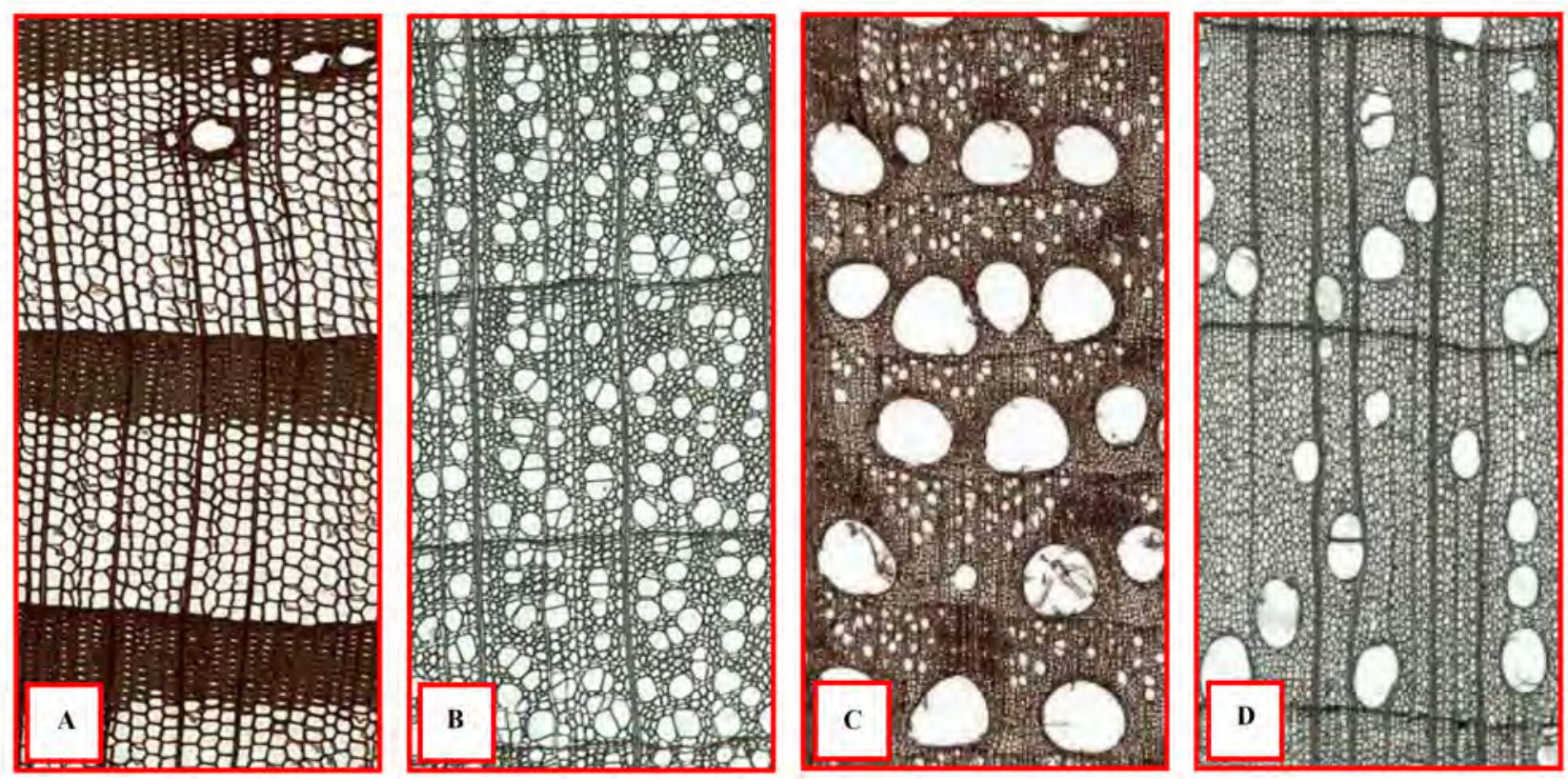

图2 不同材性树种木质部解剖。A, 无孔材, 欧洲落叶松(Larix decidua)。B, 散孔材, 小叶椴(Tilia cordata)。C, 环孔材, 夏栎 (Quercus robur)。D, 半环孔材, 胡桃(Juglans regia)。引自文献Schoch等(2004)。

Fig. 2 The anatomy of xylem in trees of differential wood porosity. A, Non-porous wood Larix decidua. B, Diffuse porous wood Tilia cordata. C, Ring porous wood Quercus robur. D, Semi-ring porous wood Juglans regia. Cited from Schoch et al., 2004.

部解剖特征被证实能够准确记录周边的环境变化且 具备气候重建的潜力(February, 1994; Fonti et al., 2010; Abrantes et al., 2013; Liang et al., 2013; VenegasGonzález et al., 2015)。

1.2 木质部解剖特征记录环境信号的机理一以 “水分输导组织”为例

维管植物木质部的主要功能是输导水分与支撑 植物体(Zimrnennann, 1983)。本文仅以木质部水分
输导组织为例, 阐述基于管孔特征对环境变化的响 应机理。长时间尺度上, 植物为适应外界的环境变 化, 不断改变其结构和功能即进化。木质部水分输 导系统经长期进化(适应及响应), 主要形成了无孔 材、环孔材、散孔材和半环孔材4类树种(图2), 这是 水分输导组织响应环境变化的典型代表 (Zimrnennann, 1983)。材性差异也决定了树体对外界环境 (尤其是水分)响应或适应策略差异。如环孔材树干

www.plant-ecology.com 
水分传输和存贮能力明显高于散孔材, 而其却更易 遭受栓塞的威胁(Tyree \& Zimmermann, 2013)。短时 间尺度上, 水分输导组织特征(如排列、大小、数量 以及细胞壁厚度等)也会随外界环境变化而呈现出 年内或年际差异(Wimmer, 2002; Giantomasi et al., 2009; Venegas-González et al., 2015)。管腔直径能够 直接影响木质部的导水能力, 根据哈根-泊肃叶定 律(Hagen-Poiseuille's law), 管腔半径增加相应输水 效率呈4次方增加, 因此管腔直径略微下降或增加 将导致水力效率大幅减少或增加 (Zimrnennann, 1983)。土壤水分可利用性能够在年际或季节水平上 影响木材的形成(Gruber et al., 2010; Eilmann et al., 2011; Vaganov et al., 2011; Wertz et al., 2013)。水分 胁迫(降水不足或高温)能通过多种途径直接或间接 地导致导管或管胞细胞变小或数量减小(Eilmann et al., 2011; Vaganov et al., 2011), 如影响木质部同化 物的积累、控制细胞的分裂、扩大和分化等(图3) (Battipaglia et al., 2010; Gruber et al., 2010)。相反, 充足的水分供应既能够直接提高细胞膨压及细胞扩 张速率导致形成较大的管腔(Tyree \& Sperry, 1989; Vaganov et al., 2011), 又能间接地通过降低生长素 浓度来减缓细胞分化或延长树木生长周期, 允许更 多及更大的导管或管胞细胞形成(Kozlowski \& Pallardy, 1997; Aloni, 2001; Vaganov et al., 2011)。值 得注意的是, 较大导管或管胞直径在增加水力效率 与气孔导度、促进光合碳增益的同时, 也使植物面 临更大的栓塞与空穴化风险(Tyree \& Sperry, 1989; Mencuccini, 2003; Sperry et al., 2006)。水分往往是干 旱条件下促进树木生长的关键, 而湿润条件下过多 的水分也会抑制树木生长。例如湿润条件下生长的 松树形成的年轮较窄且晚材比例更低, 抑制时期每 个年轮仅由1-2列早材细胞及1列较小且细胞壁较薄 的晚材细胞构成(Vaganov et al., 2011)。因此, 在全球 变化背景下, 依据树轮木质部解剖特征对环境(气候) 变化的塑性响应特性开展树轮解剖学研究, 是研究 植被与全球变化关系的重要手段(Wimmer, 2002; Stoffel \& Bollschweiler, 2008; Fonti et al., 2010)。

\section{2 树轮木质部解剖特征测定方法}

\section{1 取样设计及解剖特征选取原则}

样品及取样过程中的质量控制是树轮解剖研究 成败的关键。普通生长芯(直径一般为4.35、5.15或
$12 \mathrm{~mm}$ )、微生长芯(直径 $1.9 \mathrm{~mm}$ )或圆盘均可用于分 析。树轮木质部解剖特征相比传统年轮代用指标往 往具有更高的变异性; 林分条件(如竞争和土壤条 件)或个体特征(基因)等潜在差异均可能导致同一采 样点不同个体之间甚至同一个体不同样本间的树轮 解剖特征产生较大的变异 (Gea-Izquierdo et al., 2012; Gričar et al., 2013)。此外, 树轮木质部解剖特 征获取耗时费力, 树轮解剖相关的研究复本量常低 于传统树轮宽度研究(Gärtner \& Nievergelt, 2010)。 因此, 多数研究表明细胞年表的统计特征往往低于 宽度或密度等传统代用指标年表(Fonti \& GarcíaGonzález, 2004; Gea-Izquierdo et al., 2012; Fonti et al., 2013; Liang et al., 2013; Venegas-González et al., 2015), 尽管这些统计学参数并不代表年表记录环 境信息的强弱 (Wimmer, 2002; Fonti \& GarcíaGonzález, 2004; García-González \& Fonti, 2008)。部 分年表质量统计特征已不太适合被用来描述细胞年 表质量(Fonti \& García-González, 2004; Giantomasi et al., 2009; Gričar et al., 2013; Venegas-González et $a l ., 2015)$, 例如许多细胞年表样本总体代表性(EPS) 均未达到阈值 0.85 。因此, 适当增加样本量、合理筛 选相关性较高的样芯用于分析, 减少因年龄、样本 量、微环境或干扰等因素而导致的变异, 有利于从 树轮解剖特征中提取更准确的环境信号 (GeaIzquierdo et al., 2012; Gričar et al., 2013)。

木质部解剖特征会因其在树轮内的位置不同, 在径向(时间)和切向(空间)上呈现出较高的变异性, 如导管或管胞的大小及密度等(图2)。不同位置或尺 寸的解剖特征记录的环境信号也不尽相同(GarcíaGonzález \& Fonti, 2006; Campelo et al., 2010; Fonti et al., 2010; Carrer et al., 2015), 如García-González 和Fonti (2006)研究发现欧洲栗(Castanea sativa)早 材中最大导管面积与 3 月温度相关性较强, 小导管 面积与6月温度相关性更高, 而综合大、小导管面积 则与温度不相关。故选定测量对象数量太少, 将不 能完全反映相应时期的环境信号, 过多则会混入其 他时期形成的细胞从而导致环境信号被遮蔽 (García-González \& Fonti, 2006, 2008)。此外, 解剖 特征记录的气候信号还会因研究区域、树种、生境 或解剖特征的不同而不同(Giantomasi et al., 2009; Matisons et al., 2012; Gričar et al., 2013; Liang et al., 2013; Martin-Benito et al., 2013; Castagneri et al., 


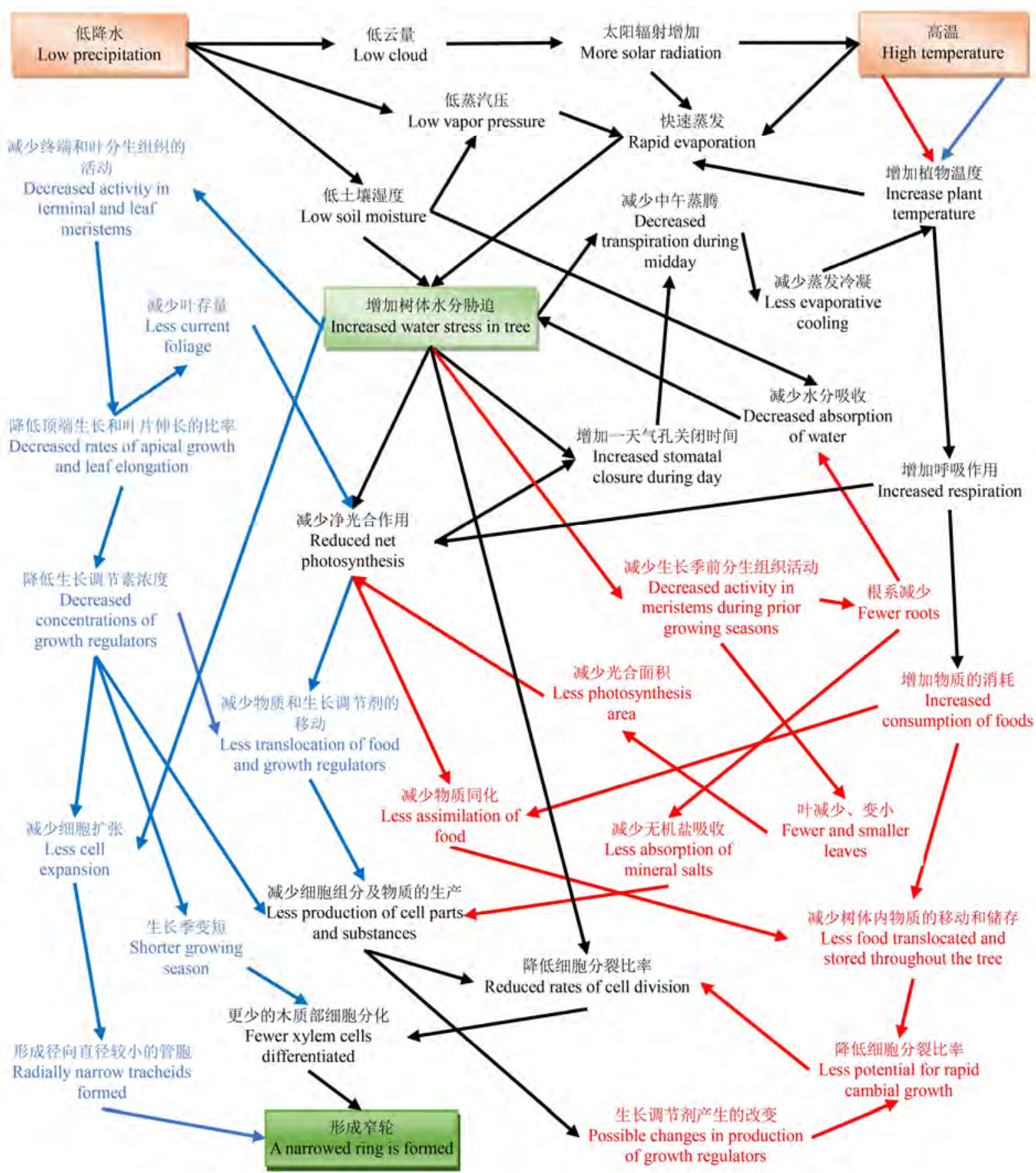

图3 低降水与高温导致树木形成窄轮的部分响应机制。红色、蓝色和黑色区域分别表示生长季前、生长季及共同的过程; 高 降水与低温导致树木形成宽轮的机制与其相反。改自Fritts (1976)。

Fig. 3 The partial response mechanisms of narrowing in tree-rings caused by low precipitation and high temperatures. The areas marked by blue, red and black indicate the processes occurring prior to the growing season, during the growing season and the entire time, respectively. The effects of high precipitation and low temperatures are in reverse, that is, ring width will increase. Modified from Fritts (1976).

2015; Venegas-González et al., 2015)。树木种类及木 质部解剖参数较多且年内空间分布复杂, 故选取适 宜的树种以及解剖参数是研究木质部解剖特征与环 境变化关系的关键。本文作者将文献和维基百科中 查到的常用木质部解剖参数及特征总结于表 1 。目
前，许多树轮木质部解剖特征(细胞年表)已被证实 能够准确记录亚年际尺度(日、月或季节)的气候变 化(Fonti et al., 2010)。针叶树研究主要集中在管胞 密度、大小及细胞壁厚度(Olano et al., 2012; Liang et al., 2013; Martin- Benito et al., 2013; Pritzkow et al., 
2014)、纤维素微纤丝角度(Xu et al., 2012)、射线薄 壁细胞数量(Olano et al., 2013)、木质部年内密度波 动(intra-annual density fluctuations, IADFs; 指正常 生长季的生长过程中断引起局部木材密度的突然变 化, 也称“伪轮”)(Campelo et al., 2015; Carvalho et al., 2015)以及树脂道(Novak et al., 2013)等方面; 而 阔叶树种研究多关注于环孔材或半环孔材早材导管 的大小及密度(Gea-Izquierdo et al., 2012; Matisons et al., 2012; Gričar et al., 2013), 也有就部分散孔材 导管开展的探索性研究, 如水青冈属(Fagus)(Sass \& Eckstein, 1995)、华木属(Betula)(Arbellay et al., 2010)、杨属(Populus)(Schume et al., 2004)、Prosopis flexuosa (Giantomasi et al., 2009)及Arbutus unedo (Battipaglia et al., 2010)等。

\section{2 样品处理方法}

树轮木质部解剖研究中样品制备方法主要分为
显微切片法和直接打磨法两大类(表2)。显微切片法 是树轮解剖学研究中最传统的方法(Fonti et al., 2010; Gärtner et al., 2014), 具有分辨率高、清晰度 好、切片便于携带保存且能制成连续切片等优点 (Fonti et al., 2010), 适用于小至细胞壁厚度、纹孔大 小及木纤维厚度等亚细胞特征的量化。传统切片(微 生长芯)制备太过复杂, 严重制约了树轮解剖学的 发展(Gärtner et al., 2014, 2015)。近年来, 随着树轮 解剖学研究的逐渐增多, 部分专业用于制作树轮木 质部大芯切片(普通生长芯)的切片机及配套软件被 相继研发出来(Gärtner \& Nievergelt, 2010; Gärtner et $a l ., 2014)$, 明显简化了样品预处理的过程(表2), 例 如运用GSL1-切片机可显著提高树轮木质部显微切 片制作与解剖特征解读的效率(Gärtner \& Nievergelt, 2010; Gärtner et al., 2014)。对于相对较大的木 质部解剖结构(如阔叶树导管或针叶树管胞), 还可

表1 常用木质部解剖参数及特征

Table 1 Types and characteristics of common anatomical parameters of xylem

\begin{tabular}{|c|c|c|c|}
\hline 类型 Type & 参数 Parameter & 特征 Feature & 作用 Function \\
\hline 导管 & \multirow{2}{*}{$\mathrm{Di}, \mathrm{Nu}, \mathrm{Ar}, \mathrm{De}, \mathrm{GF}$} & 由死细胞串联而成, 由穿孔相互衔接 & $\begin{array}{l}\text { 输导水分和无机盐 } \\
\end{array}$ \\
\hline Vessel & & $\begin{array}{l}\text { Long straight chain by dead cells, jointed each other by } \\
\text { perforations }\end{array}$ & Transport water and inorganic salt \\
\hline 管胞 & \multirow[t]{2}{*}{ Di, Nu, Ar, De, CWT } & 由单个细胞组成, 其不具穿孔 & 运输水分及矿物质, 机械支持 \\
\hline Tracheid & & Consists of single cell without perforation & Transport water and minerals, mechanical support \\
\hline 树脂道 & \multirow[t]{2}{*}{$\mathrm{Di}, \mathrm{Nu}, \mathrm{An}$} & 由分泌细胞彼此分离而形成, 拒存分泌物 & 对昆虫和病原菌防御反应的第一道防线 \\
\hline Resin canal & & $\begin{array}{l}\text { Developed as the divergence of secretory cells, storing } \\
\text { secretions }\end{array}$ & The first line of defense reaction to insects and pathogens \\
\hline 木射线 & \multirow[t]{2}{*}{$\mathrm{Nu}, \mathrm{CWT}$, An } & 由活射线薄壁细胞构成 & 径向输导液流 \\
\hline Ray & & Consists of living ray parenchyma cells & Radial transmission of sap \\
\hline 微纤丝 & \multirow[t]{2}{*}{$\mathrm{Nu}, \mathrm{An}$} & 由纤维素分子束聚合而成, 平行排列 & 细胞壁组分, 影响细胞及木材的机械性能 \\
\hline Micro-fibril & & $\begin{array}{l}\text { Aggregated by cellulose molecular beams, with parallel } \\
\text { arrangement }\end{array}$ & $\begin{array}{l}\text { Components of cell wall, affect the mechanical properties } \\
\text { of cell and wood }\end{array}$ \\
\hline
\end{tabular}

An, 角度; Ar, 面积; CWT, 细胞壁厚度; De, 密度; Di, 直径; GF, 组织特征; $\mathrm{Nu}$, 数量。

An, angle. Ar, area; CWT, cell wall thickness; De, density; Di, diameter; GF, group feature; Nu, number.

表2 主要木质部解剖方法概述

Table 2 Summary of the major methods in anatomical analysis of xylem

\begin{tabular}{|c|c|c|c|}
\hline \multirow{2}{*}{$\begin{array}{l}\text { 项目 } \\
\text { Item }\end{array}$} & \multicolumn{2}{|c|}{ 显微切片法 Micro section method } & \multirow{2}{*}{$\begin{array}{c}\text { 直接打磨法 } \\
\text { Direct polishing method }\end{array}$} \\
\hline & 传统切片 Conventional slicing & 现代切片 Contemporary slicing & \\
\hline $\begin{array}{l}\text { 适用样品类型 } \\
\text { Applicable sample type }\end{array}$ & $\begin{array}{l}\text { 微生长芯(短) } \\
\text { Micro-core (short) }\end{array}$ & $\begin{array}{l}\text { 普通生长芯(长) } \\
\text { General core (long) }\end{array}$ & $\begin{array}{l}\text { 普通生长芯或圆盘(长) } \\
\text { General core or disk (long) }\end{array}$ \\
\hline $\begin{array}{l}\text { 样品预处理流程 } \\
\text { Sample pretreatment process }\end{array}$ & $\begin{array}{l}\text { 固定、脱水、透明、浸蜡、包埋、切片、粘片、 } \\
\text { 脱蜡、染色等 } \\
\text { Fixation, dehydration, paraffin, embedding, section- } \\
\text { ing, sticky pills, dewaxing and dyeing etc. }\end{array}$ & $\begin{array}{l}\text { 切片及染色等 } \\
\text { Sectioning and staining, etc. }\end{array}$ & $\begin{array}{l}\text { 打磨、清洗及增加对比度等 } \\
\text { Grinding, cleaning and increasing } \\
\text { contrast, etc. }\end{array}$ \\
\hline $\begin{array}{l}\text { 适用尺度 } \\
\text { Applicable scale }\end{array}$ & $\begin{array}{l}\text { 细胞或亚细胞 } \\
\text { Cells or subcellular }\end{array}$ & $\begin{array}{l}\text { 细胞或亚细胞 } \\
\text { Cells or subcellular }\end{array}$ & $\begin{array}{l}\text { 细胞 } \\
\text { Cell }\end{array}$ \\
\hline $\begin{array}{l}\text { 适宜组织部位 } \\
\text { Applicable site }\end{array}$ & $\begin{array}{l}\text { 㓞皮部或木质部 } \\
\text { Phloem or xylem }\end{array}$ & $\begin{array}{l}\text { 木质部 } \\
\text { Xylem }\end{array}$ & $\begin{array}{l}\text { 木质部 } \\
\text { Xylem }\end{array}$ \\
\hline 分辨率 Resolution & 高 High & 高 High & 略低 Slightly low \\
\hline 工作量 Workload & 重 Heavy & 轻 Light & 适中 Moderate \\
\hline 主要设备 & 普通切片机和成像显微镜 & 专用切片机和成像显微镜 & 高分辨率相机或扫描仪 \\
\hline Major equipment & General microtome and imaging microscope & $\begin{array}{l}\text { Specialized microtome and imaging } \\
\text { microscope }\end{array}$ & High resolution camera or scanner \\
\hline
\end{tabular}


利用数字化成像技术从经打磨的样芯表面直接捕捉 获得解剖特征, 从而提高工作效率(Giantomasi et al., 2009; Liang et al., 2013; Venegas- González et al., 2015; 刘玉佳等, 2015)。因打磨易造成薄细胞壁断 裂或细胞腔堵满灰尘, 降低样品表面的分辨率, 故 采用直接打磨法捕捉木质部解剖结构时, 样品须经 一系列特殊的表面处理, 以提高分辨率(表2)(Fonti et al., 2010; Gärtner et al., 2015; Venegas-González et al., 2015)。如样品打磨后需用高压水(气)枪清洗样 品表面及管腔内的杂物或灰尘, 确保样品表面洁净 且管腔内无异物填充(Gärtner \& Nievergelt, 2010; Matisons et al., 2012; Gärtner et al., 2015); 低分辨率 样品需预先用深色墨水沾拭样品表面(表面暗化), 待墨迹干透再用明亮物质(如白色的粉笔、橡皮泥或 蜡等)擦试样品表面(细胞腔亮化), 以增加样品细胞 壁及腔隙间的对比度(Gärtner \& Nievergelt, 2010; Gärtner et al., 2014; Venegas- González et al., 2015)。 此外, 为确保捕捉的准确性, 避免因自动捕捉错误 而进行的频繁手动修改测量, 必须保证样品的年轮 边界清楚, 且整个样芯的表面在一个平面内。故样 品预处理质量(主要指打磨法)直接决定解剖特征解 读的效率及准确性。

样品预处理(切片或样芯)完毕即可利用超高分 辨率扫描仪(仅适用于打磨法)或高像素数码相机将 清晰的切片或样芯表面转换为数字化图像。随后, 利用专业图像分析软件或辅助测量软件 (如 WinCELL、Image-Pro Plus、ROXAS及MiVnt图像分 析系统等)自动或半自动化读取及测量木质部解剖 特征(Fonti et al., 2010; Liang et al., 2013; VenegasGonzález et al., 2015)。借助辅助测量软件目标控制 属性预设好提取目标的范围(如阔叶树导管大小及 长宽比范围等), 自动捕捉图像中细胞或腔隙等解 剖结构。结合人工辅助检查纠错, 便可高效且相对 准确地完成测量(Campelo et al., 2010; von Arx \& Carrer, 2014; Gärtner et al., 2015)。

近年来, 利用SilviScan-3设备可快速分析测定 年轮宽度、细胞数量、径向及切向直径、细胞壁厚 度、木材密度及微纤丝角度等多项宏微观年轮特征。 虽然此设备价格昂贵, 但因其测量指标多、快速精 准且不需要单独进行图像分析, 已逐渐受研究者们 青睐(Xu et al., 2012; Abrantes et al., 2013; von Arx \& Carrer, 2014; Wood et al., 2016)。需要强调的是,
无论采用哪种方法, 准确交叉定年均是精准获取树 轮木质部显微解剖特征的前提。

\section{3 解剖参数(细胞年表)标准化及去趋势}

管胞是裸子植物木质部解剖研究中最常见解剖 结构, 其在年轮内排列整齐且规则 (Fonti et al., 2010; Campelo et al., 2016)。管胞随形成时间在年轮 内呈规律性变化且同一年内形成的管胞常被作为整 体研究。管胞径向直径大小与在年轮内的相对位置 的函数被称为“管胞图像(Tracheidograms)”。个体间 或年际间管胞数量常存在差异(Vaganov et al., 2006; Carvalho et al., 2015; Vieira et al., 2015), 为比较不 同年轮间的管胞或相同时期形成的管胞特征常需要 对管胞图形进行管胞数量标准化即管胞图像标准化 (Vaganov et al., 2006; Carvalho et al., 2015; Campelo et al., 2016)。Vaganov (1990)最先提出利用某一常数 来标准化所有年份管胞数目的标准化方法, 在不改 变细胞尺寸变化曲线形状即纵坐标(径向细胞大小) 不变的情况下, “压缩”或“延伸”初始管胞图像的横 坐标(细胞数量)(Vaganov, 1990)。该方法是目前公认 的管胞图像标准化方法(Campelo et al., 2016), 适用 于管胞数量变异小的情形。当管胞数量年际间变异 较大时, 如地中海地区海岸松(Pinus pinaster)连续 两年间管胞数量差异可达到20个以上(Carvalho et al., 2015; Vieira et al., 2015), 使用该标准化方法往 往会低估观测值或损失部分显著的气候信号 (Campelo et al., 2016)。此后, 有学者将Vaganov方法 中的常数调整为相应年份内各径向管胞数量的均 值, 允许不同年份拥有各自数量的细胞去标准化 (DeSoto et al., 2011)。上述两种方法均无法确定年轮 中密度波动(IADFs)的相对比例, 这在地中海地区 生长的针阔叶树中较为常见(Battipaglia et al., 2010; de Luis et al., 2011; Campelo et al., 2015; Carvalho et $a l ., 2015)$ 。近年来, 学者们还提出了基于年轮中管 胞相对位置(距早材起始端距离)来进行管胞标准化 的方法(Campelo et al., 2016)。该方法适用于环境条 件差异较大或管胞数量变异较高的环境, 且保持了 准确的年内变化信息, 还提高了前两种方法在评估 IADFs较大或管胞数量年际变异较高的年轮内晚材 评估的准确性, 有利于更好地估测树木的生产力与 固碳能力(Campelo et al., 2016)。此外, 阔叶树中散 孔材导管具有与针叶树管胞相似的特征, 也可利用 管胞图像法标准化散孔材导管解剖特征(Grabner, 
2005)。阔叶树木质部解剖特征往往分布无规律、排 列不规则, 其大小过渡急或不呈梯度, 如环孔材导 管的大小或密度等 (Gea-Izquierdo et al., 2012; Matisons et al., 2012; Gričar et al., 2013)。针对类似 排列不规则且呈非梯度性变化的解剖特征, 常以年 轮内某部分解剖特征为对象开展研究, 不能用类似 的管胞图像法来进行标准化。

树轮解剖特征中也存在因年龄或竞争等因素而 造成的变异(Matisons et al., 2012; Gričar et al., 2013; Peters et al., 2015; Venegas-González et al., 2015), 常需选择理想去趋势方法, 剔除解剖特征序列中的 噪音(Fonti et al., 2010; Liang et al., 2013; Peters et al., 2015)。针对木质部解剖特征序列的去趋势, 实 践中往往直接运用传统方法去趋势(Fonti \& GarcíaGonzález, 2004; Giantomasi et al., 2009; Matisons et al., 2012; Gričar et al., 2013; Venegas-González et al., 2015)。针叶树管胞、阔叶树导管、IADFs、射线薄 壁细胞数量、树脂道数量及微纤丝角解剖特征均可 采用常规方法去趋势(Xu et al., 2012; Fonti et al., 2013; Olano et al., 2013; Novak et al., 2013; Campelo et al., 2015)。树轮解剖学研究中常用的去趋势方法 有线性回归(Yasue et al., 2000)、样条函数(Fonti \& García-González, 2004; Campelo et al., 2010; Gričar et al., 2013)、自回归模型(Olano et al., 2012)或负指 数函数(Fonti et al., 2013; Martin-Benito et al., 2013) 等。去趋势方法不同, 去趋势效果往往也不一样 (Carrer et al., 2015; Peters et al., 2015), 但无论采用 哪种方法都会在剔除干扰信号的同时, 损失部分低 频或高频的气候信号(Peters et al., 2015), 例如Liang 等(2013)研究发现德国东北部欧洲赤松(Pinus sylvestris)早材内细胞腔的平均面积(原始值)与日平均 最低温度显著正相关, 而利用样条函数剔除低频趋 势后, 这种显著相关也随之消失。树种特性、去趋 势目的、解剖特征类型以及木材性质等差异, 均可 能影响去趋势方法的选择(Abrantes et al., 2013; Carrer et al., 2015; Peters et al., 2015), 故选用去趋 势函数对木质部解剖特征序列进行去趋势与标准化 时应谨慎(Carrer et al., 2015; Peters et al., 2015)。另 外, 部分研究发现树轮解剖特征所呈现的年龄趋势 仅表现在树木生长的幼龄阶段(10-30年)(GeaIzquierdo et al., 2012; Liang et al., 2013; Pritzkow et al., 2014; Carrer et al., 2015)。实际研究中尽可能多
地保留气候信号远比略微延长序列长度有意义, 故 可将包含幼龄趋势的部分区段直接删除后再用于树 轮气候学分析, 巧妙地避免去趋势带来的弊端 (Gea-Izquierdo et al., 2012; Gričar et al., 2013; Liang et al., 2013; Venegas-González et al., 2015)。

\section{3 木质部解剖特征与气候关系}

\section{1 阔叶树导管}

导管是双子叶植物木质部轴向输送水分的最主 要结构, 其相关特征与水分密切相关(Zimrnennann, 1983; Fonti et al., 2010)。许多研究表明导管特征能 够准确记录周围的水分信号, 早在1994年February 就曾用南非考古遗址木炭年轮内导管直径重建了过 去的降水变化(February, 1994)。外界(土壤)水分的可 利用性也能直接或间接影响导管特征, 调整水分策 略以适应外界环境(Eilmann et al., 2011; Vaganov et al., 2011; Wertz et al., 2013)。一般来说, 干旱胁迫 (降水不足或高温)环境下, 木质部的导管往往会尺 寸变小、变量减少(Eilmann et al., 2011; Vaganov et al., 2011); 而水分供应充足时, 木质部形成的导管 往往面积更大、数量更多(Tyree \& Sperry, 1989; Vaganov et al., 2011)。干旱地区植物导管的大小或 数量均低于湿润地区(Rita et al., 2015), 如Campelo 等(2010)研究发现Quercus ilex导管面积与多月降水 量极显著正相关, 与温度相关性不显著, 从而指出 导管面积主要受生长季水分可利用性控制, 冬季冻 结事件和夏季干旱可能会导致较小的导管产生, 以 应对空穴化和栓塞。导管直径与其面临栓塞与空穴 化风险成正比(Zimrnennann, 1983; Sperry et al., 2006)。在干旱期, 较大栓塞与空穴化风险可能危及 植物的输水系统, 严重影响植物生存 (Tyree \& Sperry, 1989); 小而少的导管可降低水分输导效率, 确保其水力安全(Tyree \& Sperry, 1989; Mencuccini, 2003; Sperry et al., 2006), 如干旱条件下, Quercus canariensis通过减少早材内导管数量和直径(降低水 力导度), 保存土壤水分且避免极端负水势的发生, 以适应夏季干旱的地中海气候(Gea-Izquierdo et al., 2012)。干旱生境多强调水力安全性, 而湿润生境多 强调水力效率性(Giantomasi et al., 2009; VenegasGonzález et al., 2015)。植物还能够通过增加导管的 密度或改变导管的数量与分布等结构来提高植物的 导水率, 以规避空穴化的风险(Hacke et al., 2006; 
Loepfe et al., 2007)。管腔密度增加也是提高水力效 率的重要途径, 它可适当规避植物空穴化的风险, 但会增加空穴化或栓塞的蔓延 (Carlquist \& Hoekman, 1985)。许多研究表明导管密度与水分关 系密切且能够记录显著的水分信号(Corcuera et al., 2004; Schume et al., 2004)。导管大小常与密度负相 关(Abrantes et al., 2013; Rita et al., 2015), 导管变小 的同时, 常伴随着密度的提高(Hacke et al., 2006; Loepfe et al., 2007), 例如干旱区Ilex aquifolium 导管 大小与各季节降水显著正相关, 而导管密度与各季 节降水显著负相关(Rita et al., 2015)。也有研究发现 导管密度并不能像导管面积那样准确记录外界环境 信号(Sass \& Eckstein, 1995; Campelo et al., 2010; Leal et al., 2011), 如半环孔材Quercus suber和散孔 材Fagus sylvatica (Sass \& Eckstein, 1995; Leal et al., 2011)的导管密度几乎恒定。

温度能够影响木质部导管特征已被许多研究所 证实(Fonti \& García-González, 2004; Pritzkow et al., 2016)。例如, Matisons等(2012)研究发现拉脱维亚地 区Quercus robur早材导管面积与上一年5月、6月、9 月及 12 月至当年 4 月温度显著正相关, 并指出气候 变化可能导致该树种木材形成对冬季温度和生长季 长度的敏感性降低; 学者们还利用Quercus robur导 管参数重建了冬季最低温度(Pritzkow et al., 2016)。 温度可通过影响光合作用与呼吸作用调控同化物的 积累与分配, 影响木质部导管特征(Barbaroux \& Bréda, 2002)。早材导管相关特征多受生长季前期或 生长季初期的温度影响。例如, Castanea sativa早材 导管大小主要与导管生长的两个关键生理时期, 即 前一年生长季结束前(储备存储阶段)和形成层活动 开始时 (细胞分裂和导管分化阶段) 的温度相关 (Fonti \& García-González, 2004)。部分研究证实环孔 材早材中第一列导管在树木萌芽时或萌芽前形成 (Suzuki et al., 1996; Schmitt et al., 2000), 形成时间 早于光合活性的恢复, 早材形成初期的物质由前一 个生长季存储的同化物提供(Barbaroux \& Bréda, 2002)。早材宽度与前一年晚材宽度的相关性常明显 高于与当年晚材宽度的相关性, 也验证了该解释 (Fonti \& García-González, 2004)。此外, 温度可通过 影响细胞分裂与分化的关系及生长周期直接影响导 管的数量及大小等特征(Fonti \& García-González, 2004; Venegas-González et al., 2015), 如Pérez-De-Lis
等(2016)发现春季物候会影响 Quercus robur 及 Quercus pyrenaica早材导管的形成, 温带地区因气 温较早达到有效积温, 可形成更大的导管。有关阔 叶晚材导管的研究较少, 其形成可能与生长季或生 长季末降水及温度密切相关(Fontiet al., 2010)。

\section{2 针叶树管胞}

管胞是裸子植物木质部最主要的组成部分, 是 运输水分和矿物质的主要通道(表1)。许多研究表明 管胞特征与水分条件关系密切(Fonti et al., 2010; Gea-Izquierdo et al., 2012), 如Martin-Benito等(2013) 发现前一年秋季和当年春、夏季的降水对地中海森 林中欧洲黑松(Pinus nigra)和欧洲赤松径向生长十 分有利, 尤其是对早材管胞直径增大及细胞壁加厚 至关重要; 当年夏季水分利用率较低会导致欧洲赤 松管胞数量减少、腔径增加及细胞壁变薄, 晚材比 例降低; 当年夏季的降水量及标准化降水蒸发指数 (standardized precipitation evapotranspiration index, SPEI)与黑松的管胞数量及壁厚正相关, 而当年秋 季的降水量及 SPEI与黑松的管胞数量及壁厚负相 关。土壤水分既能直接影响木质部细胞的分裂、扩 大以及分化, 还会间接影响树木生长期长短, 导致 针叶树管胞特征发生改变, 最终影响年轮宽窄(图 3)(Battipaglia et al., 2010; Gruber et al., 2010; Eilmann et al., 2011; Vaganov et al., 2011) , 如在不利 的水分条件下, 欧洲赤松细胞伸长与细胞壁加厚阶 段持续时间明显缩短, 木质部细胞活动提早结束约 4周, 致使窄轮发生(Gruber et al., 2010); 而在灌溉 条件下, 欧洲赤松早晚材转变时间比干旱条件下推 迟2-4周, 细胞停止活动推迟约5周, 径向增量明显 高于干旱条件下的欧洲赤松(Eilmann et al., 2011)。 针叶树管胞与阔叶树导管对水分环境响应策略一 样, 也遵循水力效率性和安全性的权衡(Zimrnennann, 1983; Sperry et al., 2006)。

温度可通过影响多种生理过程直接或间接影响 木质部管胞特征(图3)(Vaganov et al., 2006, 2011; Novak et al., 2013); 其中最直接的影响就是通过控 制形成层活动调整树木的生长周期。生长季开始时, 外界环境温度的略微波动将导致形成层活动开始时 间发生明显改变(Leikola, 1969), 只有当环境温度高 于形成层活动的最低阈值温度时, 树木生长才可能 被触发(Denne, 1971)。模型预测发现温度上升1 ${ }^{\circ} \mathrm{C}$ 可导致Pinus thunbergii形成层活动开始时间提前 
4-5天, 结束期推迟 4-6 天, 生长季延长 8-11 天 (Rossi et al., 2011)。形成层细胞产生速率在很大程 度上由同期温度决定, 如Deslauriers等(2003)发现北 方针叶林内香脂冷杉(Abies balsamea)年轮形成各时 期管胞数量变化剧烈, 早材形成时期可短至1周, 晚 材形成周期短至5-10天。低温可缩短形成层活动周 期、降低细胞分裂速率, 导致木质部晚材的比例降 低(Gričar et al., 2006); 高温则会延长生长季, 增加 树轮中晚材的比例(Vaganov et al., 2006)。温度对树 木管胞解剖特征的影响会随研究区域发生变化, 高 纬度地区树木形成层细胞增大阶段细胞伸长的时间 明显短于低纬度地区植物(Vaganov et al., 2006), 其 对外界温度变化响应更迅速(Deslauriers \& Morin, 2005)。影响早材管胞直径的初夏温度介于 $5-14{ }^{\circ} \mathrm{C}$, 接近或超出该界限温度时, 温度对管胞直径的影响 减弱, 如Vaganov (1996)发现北方树线附近欧洲落 叶松早材内管胞直径会因长期的夏季升温而显著增 加, 而Denne (1971)则发现将欧洲赤松幼苗的培养 温度从 $17.5{ }^{\circ} \mathrm{C}$ 增加到 $27.5{ }^{\circ} \mathrm{C}$, 管胞直径仅增加 $10 \%$ 。另外, 管胞相关特征也能准确记录外界的温 度变化(Vaganov et al., 2011; Liang et al., 2013)。例 如Panyushkina等(2003)研究发现西伯利亚东北部落 叶松(Larix cajanderi), 早晚材管胞直径均与 6 月温 度正相关, 晚材管胞直径(壁厚)与7月温度负(正)相 关; 管胞数量与 5 月温度负相关, 与 6 月温度正相关; 管胞直径及数量可被用来重建1642年以来的夏季温 度。一般来说, 早材内的管胞特征(如大小、数量、 细胞壁厚度等)多受早春与前一年冬季温度的影响, 晚材内的管胞特征常与晚夏温度有关, 而早晚材过 渡区的管胞特征多受春末夏初温度的影响(Novak et al., 2013)。

\section{3 针叶树树脂道}

树脂道为分泌道的一种。松属、云杉属及落叶 松属等部分针叶树中常常包含树脂道。目前, 有关 树脂道与气候变化关系的研究相对较少(Rigling et al., 2003; Wimmer \& Grabner, 1997, 2000)。Wimmer 和Grabner (1997)曾尝试将挪威云杉(Picea abies)树 轮中树脂道密度看作树轮气候学变量进行年轮气候 学分析, 发现树脂道密度年表相比宽度在统计上稳 定且具有高敏感度和标准偏差, 但信噪比较低, 并 指出树脂道密度独立于树轮宽度, 能够指代不同的 气候信号, 年度或夏季降雨量增加则会导致树脂道
的频率减小或尺寸变小。Wimmer和Vetter (1999)对 挪威云杉树脂道作进一步研究发现树脂道多位于早 晚材过渡区, 干燥年份形成较多树脂道、轴向也较 长, 树脂道密度与夏季温度显著正相关。Wimmer 和Grabner (2000)在研究德国挪威云杉树脂道密度 时, 进一步指出即使该指标记录的气候信号不太明 显(仅与6月温度正相关), 但仍具有记录气候信号的 巨大潜力。Rigling等(2003)研究了灌溉对欧洲赤松 径向生长和树脂道密度的影响, 结果发现灌溉导致 径向生长增加, 树脂道密度总体上有所下降, 但早 材内树脂道的数量增加; 树脂道密度随酷热的夏季 温度激增; 尽管径向生长与树脂道密度正相关, 但 二者的气候响应明显不同。上述研究表明：高温和 干旱诱导产生的乙烯可能在上述过程中起重要作用 (Rodríguez-García et al., 2015), 恶劣的环境条件(如 高温、干旱和严寒)常常会导致针叶树木质部树脂道 的出现频率增加且尺寸变大(Wimmer \& Vetter, 1999; Rigling et al., 2003; Rodríguez-García et al., 2015)。然而, Rodríguez-García等(2015)发现树脂道 特征与水分密切相关, 水分亏缺的冬季及低蒸发的 春季均伴随着单位面积上树脂道面积的增加, 夏季 更高的土壤含水量或较低的水分亏缺可能导致树脂 道增大且出现频率升高。综上所述, 尽管树脂道植 物种类有限, 但因树脂道特征测量较易且常记录着 与径向生长不同的信号, 故值得加强对该解剖特征 的研究。

\section{4 特定“痕迹”及其他解剖特征}

特定环境事件会影响形成层的正常活动，在年 轮中留下某些特殊痕迹; 这些不连续的“痕迹”常被 用来重建该特定环境事件(Wimmer, 2002; Stoffel \& Bollschweiler, 2008)。其中, 关于IADFs的研究最多 (de Micco et al., 2016)。水分的季节性波动影响形成 层活动而触发IADFs的产生是其最主要的形成原因, 如 Battipaglia等(2010)发现地中海地区干旱地点 Arbutus unedo 早材中IADFs 是生长季初期干旱胁迫 的结果, 而湿润地点晚材中IADFs则是由生长季末 有利的水湿条件所引起; Venegas-González等(2015) 则发现巴西热带Pinus caribaea早材中IADFs是夏 (雨)季充沛的降水所触发, 而晚材中IADFs则是由 生长季末充足的水分再次引发生长所致。此外, IADFs还会因其他生物或非生物因素导致落叶后的 低光合而触发, 其形成与结构特性取决于很多因素, 
详见de Micco等(2016)。

另外，森林火灾会导致部分形成层被烧死，而 形成特殊的“猫脸痕” (Smith \& Sutherland, 1999); 洪水等特殊的气候事件会在木质部解剖结构中留下 特殊痕迹, 即“洪灾轮”, 根据树轮解剖结构中“洪灾 轮”的发生情况可重建过去洪水的发生历史(Arbellay et al., 2010; Wertz et al., 2013); 高海拔地区或北 方林线, 寒秋或夏末温度的急剧变冷会造成年轮晚 材细胞壁变薄, 形成所谓的“亮轮” (Wang et al., 2002); 生长季内的异常低温事件(温度降至0 ${ }^{\circ} \mathrm{C}$ 以 下)会导致形成层分化出的未成熟木质部细胞无法 完成次生壁加厚及木质化过程, 细胞脱水还会使未 正常发育的细胞因挤压而变形, 在年轮细胞结构上 出现明显的异常标志即 “霜轮” (D’Arrigo et al., 2001)。上述“痕迹”均能准确记录周围的环境信号, 并被用作年轮气候分析。此外, 未木质化或未完全 木质化的木质部细胞会被固绿染成蓝色, 这些特殊 的“蓝轮”可被用作分析木质化过程与气候要素的关 系(Piermattei et al., 2014); 树轮木质部纤维素微纤 丝角度(Xu et al., 2012)、射线薄壁细胞数量(Olano et al., 2013)等解剖参数, 也被证实能够准确记录周围 的环境信号。

\section{4 研究展望}

树轮木质部解剖使树木生长与环境变化关系的 研究在时间尺度上由年际尺度精确到月或季节尺 度, 空间上由整个生长轮分辨到细胞或亚细胞尺度 (Fonti et al., 2010)。木质部解剖特征(如导管或管胞 的尺寸、密度及壁厚等)记录着与传统树轮指标不同 的气候信号(Campelo et al., 2010; Liang et al., 2013; Venegas-González et al., 2015), 是对传统树木年轮 学的继承与发展。树轮木质部解剖为从生理学上解 释年轮-气候响应关系奠定了基础, 为研究全球变 化背景下物种的适应过程与响应策略提供了新视 野, 并为科学评估未来气候变化对植被的影响提供 了依据(Fritts, 1976; Fonti et al., 2010; Liang et al., 2013)。考虑到树轮解剖学研究现状及其在全球变化 研究中的广阔前景, 未来可在以下几个重要方面开 展研究:

(1)探究木质部解剖结构在径向和切向上的时 空变化规律及其与气候变化的关系; 进一步探索其 他细胞或亚细胞尺度特征记录气候变化的潜力, 如
木纤维、纹孔结构和木质化程度等; 并将研究对象 由乔木拓展到藤本、灌木以及草本等其他生活型。

(2)探索树木对环境变化塑性响应的阈值, 充分 理解木质部形成对气候变化的响应策略及适应过 程; 加强对不同频率气候信号识别和提取, 提高气 候重建精确性。

(3)探寻树轮各代用指标对气候变化响应差异 的机理，评估各树轮代用指标间的协同与拮抗效 应; 结合形成层活动等物候动态及对特定气候环境 事件的连续监测, 确定各个时期主要气候因子对树 轮形成的具体作用及贡献量, 进一步明确树木生长 与气候因子的关系。

基金项目 国家自然科学基金(41471168 和 31370463)、中央高校基本科研业务费专项资金 (2572016AA32和2572014DA05)和长江学者和创新 团队发展计划(IRT-15R09)项目。

致谢 感谢东北林业大学生态研究中心研究生杨婧 雯及张旭在文献收集工作中给予的帮助。

\section{参考文献}

Abrantes J, Campelo F, García-González I, Nabais C (2013). Environmental control of vessel traits in Quercus ilex under Mediterranean climate: Relating xylem anatomy to function. Trees, 27, 655-662.

Aloni R (2001). Foliar and axial aspects of vascular differentiation: Hypotheses and evidence. Journal of Plant Growth Regulation, 20, 22-34.

Arbellay E, Stoffel M, Bollschweiler M (2010). Wood anatomical analysis of Alnus incana and Betula pendula injured by a debris-flow event. Tree Physiology, 30, 12901298.

Barbaroux C, Bréda N (2002). Contrasting distribution and seasonal dynamics of carbohydrate reserves in stem wood of adult ring-porous sessile oak and diffuse-porous beech trees. Tree Physiology, 22, 1201-1210.

Battipaglia G, de Micco V, Brand WA, Linke P, Aronne G, Saurer M, Cherubini P (2010). Variations of vessel diameter and $\delta^{13} \mathrm{C}$ in false rings of Arbutus unedo L. reflect different environmental conditions. New Phytologist, 188, 1099-1112.

Briffa K, Osborn T, Schweingruber F (2004). Large-scale temperature inferences from tree rings: A review. Global and Planetary Change, 40, 11-26.

Campelo F, Nabais C, Carvalho A, Vieira J (2016). tracheideR -An R package to standardize tracheidograms. Dendrochronologia, 37, 64-68.

Campelo F, Nabais C, Gutiérrez E, Freitas H, García-González I (2010). Vessel features of Quercus ilex L. growing under Mediterranean climate have a better climatic signal than tree-ring width. Trees, 24, 463-470. 
Campelo F, Vieira J, Battipaglia G, de Luis M, Nabais C, Freitas H, Cherubini P (2015). Which matters most for the formation of intra-annual density fluctuations in Pinus pinaster: Age or size? Trees, 29, 237-245.

Carlquist S, Hoekman DA (1985). Ecological wood anatomy of the woody southern Californian flora. IAWA Journal, 6, 319-347.

Carrer M, von AG, Castagneri D, Petit G (2015). Distilling allometric and environmental information from time series of conduit size: The standardization issue and its relationship to tree hydraulic architecture. Tree Physiology, 35, 27-33.

Carvalho A, Nabais C, Vieira J, Rossi S, Campelo F (2015). Plastic response of tracheids in Pinus pinaster in a waterlimited environment: Adjusting lumen size instead of wall thickness. PLOS ONE, 10, e0136305. doi: 10.1371/journal. pone. 0136305.

Castagneri D, Petit G, Carrer M (2015). Divergent climate response on hydraulic-related xylem anatomical traits of Picea abies along a 900-m altitudinal gradient. Tree Physiology, 35, 1378-1387.

Corcuera L, Camarero JJ, Gil-Pelegrín E (2004). Effects of a severe drought on growth and wood anatomical properties of Quercus faginea. IAWA Journal, 25, 185-204.

D’Arrigo R, Frank D, Jacoby G, Pederson N (2001). Spatial response to major volcanic events in or about AD 536, 934 and 1258: Frost rings and other dendrochronological evidence from Mongolia and Northern Siberia: comment on RB Stothers, 'Volcanic dry fogs, climate cooling, and plague pandemics in Europe and the Middle East'. Climatic Change, 49, 239-246.

de Luis M, Novak K, Raventós J, Gričar J, Prislan P, Čufar K (2011). Climate factors promoting intra-annual density fluctuations in Aleppo pine (Pinus halepensis) from semiarid sites. Dendrochronologia, 29, 163-169.

de Micco V, Campelo F, Luis MD, Brauning A, Grabner M, Battipaglia G (2016). Intra-annual density fluctuations in tree rings: How, when, where, and why? IAWA Journal, 37, 232-259.

Denne M (1971). Temperature and tracheid development in Pinus sylvestris seedlings. Journal of Experimental Botany, 22, 362-370.

Deslauriers A, Morin H (2005). Intra-annual tracheid production in balsam fir stems and the effect of meteorological variables. Trees, 19, 402-408.

Deslauriers A, Morin H, Begin Y (2003). Cellular phenology of annual ring formation of Abies balsamea in the Québec boreal forest (Canada). Canadian Journal of Forest Research, 33, 190-200.

DeSoto L, de la Cruz M, Fonti P (2011). Intra-annual patterns of tracheid size in the Mediterranean tree Juniperus thurifera as an indicator of seasonal water stress. Canadian Journal of Forest Research, 41, 1280-1294.

Eilmann B, Zweifel R, Buchmann N, Pannatier EG, Rigling A (2011). Drought alters timing, quantity, and quality of wood formation in Scots pine. Journal of Experimental
Botany, 62, 2763-2771.

Esper J, Büntgen U, Frank DC, Nievergelt D, Liebhold A (2007). 1200 years of regular outbreaks in alpine insects. Proceedings of the Royal Society of London B: Biological Sciences, 274, 671-679.

Esper J, Cook ER, Schweingruber FH (2002). Low-frequency signals in long tree-ring chronologies for reconstructing past temperature variability. Science, 295, 2250-2253.

February EC (1994). Rainfall reconstruction using wood charcoal from two archaeological sites in south Africa. Quaternary Research, 42, 100-107.

Fonti P, Bryukhanova MV, Myglan VS, Kirdyanov AV, Naumova OV, Vaganov EA (2013). Temperature-induced responses of xylem structure of Larix sibirica (Pinaceae) from the Russian Altay. American Journal of Botany, 100, 1332-1343.

Fonti P, García-González I (2004). Suitability of chestnut earlywood vessel chronologies for ecological studies. New Phytologist, 163, 77-86.

Fonti P, von Arx G, García-González I, Eilmann B, SassKlaassen U, Gärtner H, Eckstein D (2010). Studying global change through investigation of the plastic responses of xylem anatomy in tree rings. New Phytologist, 185, 42-53.

Fritts HC (1976). Tree Rings and Climate. Elsevier, Amsterdam, the Netherland.

García-González I, Fonti P (2006). Selecting earlywood vessels to maximize their environmental signal. Tree Physiology, 26, 1289-1296.

García-González I, Fonti P (2008). Ensuring a representative sample of earlywood vessels for dendroecological studies: An example from two ring-porous species. Trees, 22, 237244.

Gärtner H, Cherubini P, Fonti P, von Arx G, Schneider L, Nievergelt D, Verstege A, Bast A, Schweingruber FH, Büntgen U (2015). A technical perspective in modern tree-ring research-How to overcome dendroecological and wood anatomical challenges. Journal of Visualized Experiments, 97, e52337. doi: 10.3791/52337.

Gärtner H, Lucchinetti S, Schweingruber FH (2014). New perspectives for wood anatomical analysis in dendrosciences: The GSL1-microtome. Dendrochronologia, 32, 4751.

Gärtner H, Nievergelt D (2010). The core-microtome: A new tool for surface preparation on cores and time series analysis of varying cell parameters. Dendrochronologia, 28, 85-92.

Gea-Izquierdo G, Fonti P, Cherubini P, Martín-Benito D, Chaar H, Cañellas I (2012). Xylem hydraulic adjustment and growth response of Quercus canariensis Willd. to climatic variability. Tree Physiology, 32, 401-423.

Giantomasi MA, Junent FAR, Villagra PE, Srur AM (2009). Annual variation and influence of climate on the ring width and wood hydrosystem of Prosopis flexuosa DC. trees using image analysis. Trees, 23, 117-126.

Grabner M (2005). Functional Tree Ring Analysis: Wood as an 
Information Source to Understand Physiological, Environmental and Technological Questions. PhD dissertation, University of Natural Resources and Life Sciences, Vienna.

Gričar J, de Luis M, Hafner P, Levanič T (2013). Anatomical characteristics and hydrologic signals in tree-rings of oaks (Quercus robur L.). Trees, 27, 1669-1680.

Gričar J, Zupančič M, Čufar K, Koch G, Schmitt U, Oven P (2006). Effect of local heating and cooling on cambial activity and cell differentiation in the stem of Norway spruce (Picea abies). Annals of Botany, 97, 943-951.

Gruber A, Strobl S, Veit B, Oberhuber W (2010). Impact of drought on the temporal dynamics of wood formation in Pinus sylvestris. Tree Physiology, 30, 490-501.

Hacke UG, Sperry JS, Wheeler JK, Castro L (2006). Scaling of angiosperm xylem structure with safety and efficiency. Tree Physiology, 26, 689-701.

Kozlowski TT, Pallardy SG (1997). Growth Control in Woody Plants. Academic Press, New York.

Leal S, Sousa VB, Knapic S, Louzada JL, Pereira H (2011). Vessel size and number are contributors to define wood density in cork oak. European Journal of Forest Research, 130, 1023-1029.

Leikola M (1969). The influence of environmental factors on the diameter growth of forest trees: Auxanometric study. Acta Forestalia Fennica, 92, 59-88.

Liang W, Heinrich I, Simard S, Helle G, Liñán ID, Heinken T (2013). Climate signals derived from cell anatomy of Scots pine in NE Germany. Tree Physiology, 33, 833-844.

Liu YJ, Zhu LJ, Su JJ, Wang XC (2015). Impact of decreasing precipitation on Larix gmelinii radial growth in Maoershan, Xiaoxing'an Mountain, China. Acta Ecologica Sinica, 35, 4527-4537. (in Chinese with English abstract) [刘玉佳, 朱良军, 苏金娟, 王晓春 (2015). 模拟降水减 少对帽儿山地区兴安落叶松径向生长的影响. 生态学 报, 35, 4527-4537.]

Loepfe L, Martinez-Vilalta J, Pinol J, Mencuccini M (2007). The relevance of xylem network structure for plant hydraulic efficiency and safety. Journal of Theoretical Biology, 247, 788-803.

Martin-Benito D, Beeckman H, Canellas I (2013). Influence of drought on tree rings and tracheid features of Pinus nigra and Pinus sylvestris in a mesic Mediterranean forest. European Journal of Forest Research, 132, 33-45.

Matisons R, Elferts D, Brūmelis G (2012). Changes in climatic signals of English oak tree-ring width and cross-section area of earlywood vessels in Latvia during the period 1900-2009. Forest Ecology and Management, 279, 34-44.

Mencuccini M (2003). The ecological significance of long-distance water transport: Short-term regulation, long-term acclimation and the hydraulic costs of stature across plant life forms. Plant, Cell \& Environment, 26, 163-182.

Moberg A, Sonechkin DM, Holmgren K, Datsenko NM, Karlén W (2005). Highly variable northern hemisphere temperatures reconstructed from low- and high-resolution proxy data. Nature, 433, 613-617.

Novak K, Luís MD, Raventós J, Čufar K (2013). Climatic signals in tree-ring widths and wood structure of Pinus halepensis in contrasted environmental conditions. Trees, 27, 927-936.

Olano JM, Arzac A, García-Cervigón AI, Arx G, Rozas V (2013). New star on the stage: Amount of ray parenchyma in tree rings shows a link to climate. New Phytologist, 198, 486-495.

Olano JM, Eugenio M, García-Cervigón AI, Folch M, Rozas V (2012). Quantitative tracheid anatomy reveals a complex environmental control of wood structure in continental Mediterranean climate. International Journal of Plant Sciences, 173, 137-149.

Panyushkina IP, Hughes MK, Vaganov EA, Munro MA (2003). Summer temperature in northeastern Siberia since 1642 reconstructed from tracheid dimensions and cell numbers of Larix cajanderi. Canadian Journal of Forest Research, 33, 1905-1914.

Pérez-De-Lis G, Rossi S, Vázquez-Ruiz RA, Rozas V, GarcíaGonzález I (2016). Do changes in spring phenology affect earlywood vessels? Perspective from the xylogenesis monitoring of two sympatric ring-porous oaks. New Phytologist, 209, 521-530.

Peters RL, Groenendijk P, Vlam M, Zuidema PA (2015). Detecting long-term growth trends using tree rings: A critical evaluation of methods. Global Change Biology, 21, 2040-2054.

Piermattei A, Crivellaro A, Carrer M, Urbinati C (2014). The "blue ring": Anatomy and formation hypothesis of a new tree-ring anomaly in conifers. Trees, 29, 455-461.

Pritzkow C, Heinrich I, Grudd H, Helle G (2014). Relationship between wood anatomy, tree-ring widths and wood density of Pinus sylvestris L. and climate at high latitudes in northern Sweden. Dendrochronologia, 32, 295-302.

Pritzkow C, Wazny T, Heußner KU, Słowiński M, Bieber A, Liñán ID (2016). Minimum winter temperature reconstruction from average earlywood vessel area of european European oak (Quercus robur) in N-Poland. Palaeogeography Palaeoclimatology Palaeoecology, 449, 520-530.

Rigling A, Brühlhart H, Bräker OU, Forster T, Schweingruber FH (2003). Effects of irrigation on diameter growth and vertical resin duct production in Pinus sylvestris L. on dry sites in the central Alps, Switzerland. Forest Ecology \& Management, 175, 285-296.

Rita A, Cherubini P, Leonardi S, Todaro L, Borghetti M (2015). Functional adjustments of xylem anatomy to climatic variability: Insights from long-term Ilex aquifolium tree-ring series. Tree Physiology, 35, 817-828.

Rodríguez-García A, Martín JA, López R, Mutke S, Pinillos F, Gil L (2015). Influence of climate variables on resin yield and secretory structures in tapped Pinus pinaster Ait. in central Spain. Agricultural \& Forest Meteorology, 202, 83-93.

Rossi S, Deslauriers A, Griçar J, Seo JW, Rathgeber CB, Anfodillo T, Morin H, Levanic T, Oven P, Jalkanen R (2008).

www.plant-ecology.com 
Critical temperatures for xylogenesis in conifers of cold climates. Global Ecology and Biogeography, 17, 696-707.

Rossi S, Morin H, Deslauriers A, Plourde PY (2011). Predicting xylem phenology in black spruce under climate warming. Global Change Biology, 17, 614-625.

Sass U, Eckstein D (1995). The variability of vessel size in beech (Fagus sylvatica L.) and its ecophysiological interpretation. Trees, 9, 247-252.

Schmitt U, Möller R, Eckstein D (2000). Seasonal wood formation dynamics of beech (Fagus sylvatica L.) and black locust (Robinia pseudoacacia L.) as determined by the "pinning" technique. Angewandte Botanik, 74, 10-16.

Schoch WH, Heller I, Schweingruber FH, Kienast F (2004). Wood Anatomy of Central European Species. http://www. woodanatomy.ch. Cited: 2016-09-16.

Schume H, Grabner M, Eckmüllner O (2004). The influence of an altered groundwater regime on vessel properties of hybrid poplar. Trees, 18, 184-194.

Smith KT, Sutherland EK (1999). Fire-scar formation and compartmentalization in oak. Canadian Journal of Forest Research, 29, 166-171.

Sperry JS, Hacke UG, Pittermann J (2006). Size and function in conifer tracheids and angiosperm vessels. American Journal of Botany, 93, 1490-1500.

Stoffel M, Bollschweiler M (2008). Tree-ring analysis in natural hazards research? An overview. Natural Hazards and Earth System Science, 8, 187-202.

Suzuki M, Yoda K, Suzuki H (1996). Phenological comparison of the onset of vessel formation between ring-porous and diffuse-porous deciduous trees in a Japanese temperate forest. IAWA Journal, 17, 431-444.

Tyree MT, Sperry JS (1989). Vulnerability of xylem to cavitation and embolism. Annual Review of Plant Biology, 40, 19-36.

Tyree MT, Zimmermann MH (2013). Xylem Structure and the Ascent of Sap. Springer, Berlin.

Ursache R, Nieminen K, Helariutta Y (2013). Genetic and hormonal regulation of cambial development. Physiologia Plantarum, 147, 36-45.

Vaganov EA (1990). The Tracheidogram Method in Tree-Ring Analysis and Its Application. Methods of Dendrochronology: Applications in the Environmental Science. Kluwer Academic Publishers, Dordrecht, the Netherlands. 6375.

Vaganov EA (1996). Recording of Warming in Current Century by Tracheids of the Annual Tree Rings. Doklady Akademii Nauk, Moscow, Russia.

Vaganov EA, Anchukaitis KJ, Evans MN (2011). How well understood are the processes that create dendroclimatic records? A mechanistic model of the climatic control on conifer tree-ring growth dynamics. Dendroclimatology, 11, 37-75.

Vaganov EA, Hughes MK, Shashkin AV (2006). Growth Dynamics of Conifer Tree Rings. Springer, Berlin.
Venegas-González A, von Arx G, Chagas MP, Tomazello Filho M (2015). Plasticity in xylem anatomical traits of two tropical species in response to intra-seasonal climate variability. Trees, 29, 423-435.

Vieira J, Campelo F, Rossi S, Carvalho A, Freitas H, Nabais C (2015). Adjustment capacity of maritime pine cambial activity in drought-prone environments. PLOS ONE, 10, e0126223. doi:10.1371/journal.pone.0126223.

von Arx G, Carrer M (2014). ROXAS-A new tool to build centuries-long tracheid-lumen chronologies in conifers. Dendrochronologia, 32, 290-293.

Wang LL, Payette S, Bégin Y (2002). Relationships between anatomical and densitometric characteristics of black spruce and summer temperature at tree line in northern Quebec. Canadian Journal of Forest Research, 32, 477-486.

Wertz EL, St George S, Zeleznik JD (2013). Vessel anomalies in Quercus macrocarpa tree rings associated with recent floods along the Red River of the North, United States. Water Resources Research, 49, 630-634.

Wimmer R (2002). Wood anatomical features in tree-rings as indicators of environmental change. Dendrochronologia, 20, 21-36.

Wimmer R, Grabner M (1997). Effects of climate on vertical resin duct density and radial growth of norway spruce [Picea abies (L.) Karst.]. Trees, 11, 271-276.

Wimmer R, Grabner M (2000). A comparison of tree-ring features in Picea abies as correlated with climate. IAWA Journal, 21, 403-416.

Wimmer R, Vetter RE (1999). Tree-ring analysis biological, methodological and environmental aspects. In: Wimmer R, Grabner M, Strumia G eds. Significance of Vertical Ducts in the Tree Rings of Spruce. CABI Publishing, London. 1107-1110.

Wood LJ, Smith DJ, Hartley ID (2016). Predicting softwood quality attributes from climate data in interior British Columbia, Canada. Forest Ecology and Management, 361, 81-89.

Xu JM, Lv JX, Bao FC, Evans R, Downes G, Huang RF, Zhao YK (2012). Cellulose microfibril angle variation in Picea crassifolia tree rings improves climate signals on the Tibetan Plateau. Trees, 26, 1007-1016.

Yang B, Qin C, Wang J, He M, Melvin TM, Osborn TJ, Briffa KR (2014). A 3,500-year tree-ring record of annual precipitation on the northeastern Tibetan Plateau. Proceedings of the National Academy of Sciences of the United States of America, 111, 2903-2908.

Yasue K, Funada R, Kobayashi O, Ohtani J (2000). The effects of tracheid dimensions on variations in maximum density of Picea glehnii and relationships to climatic factors. Trees, 14, 223-229.

Zimrnennann M (1983). Xylem Structure and the Ascent of Sap. Springer, Berlin, Germany.

责任编委: 罗天祥 责任编辑: 王 葳 